\title{
Deep neck flexor endurance in university students: normative data and reliability
}

\author{
Su-chang Lee, Ye-rin Lee, Seong-kwang Yu, Dong-kwon Seo \\ Department of Physical Therapy, College of Medical Science, Konyang University, Daejeon, Republic of Korea
}

Objective: Deep neck flexor muscle endurance (DNFET) is important to cervical pain patients. However, there is no normative data of the DNFET hold time of Korean university students. The purpose of this study was to provide normative data and the reliability of the DNFET times of Korean university students and to compare the DNFET hold times between male and female subjects.

Design: Cross-sectional study.

Methods: The participants included 39 male and 39 female students with no cervical pain. Each DNFET was measured while the subjects kept their chin tucked in while in a supine (hook-lying) position and with the head lifted $2.5 \mathrm{~cm}$ off the bed. The DNFET was conducted on each subject twice and the mean values were obtained. After each measurement, the participants rested for 5 minutes. Inter-rater reliability was measured by intraclass correlation coefficient (ICC) by three separate evaluators.

Results: The inter-rater reliability was good, showing an $\operatorname{ICC}(2,3)$ value $=0.785(95 \%$ confidence interval, $0.370-0.942)$. The DNFET time scores for men and women were $25.14 \pm 9.96$ seconds and $15.23 \pm 6.10$ seconds, respectively, in which the time scores of the men were significantly longer compared to women $(p<0.05)$.

Conclusions: Asymptomatic men displayed higher DNFET scores than women. This study can help clinicians test cervical function of patients and set an interventional goal. These findings serve as a basis that insists Korean women to increase their amount of physical activity.

Key Words: Neck muscles, Physical endurance, Statistical data interpretation

\section{Introduction}

Approximately $70 \%$ of the total population experience neck pain more than once a lifetime [1]. Every year, the number of smart mobile users is increasing, and neck pain occurs mostly due to assuming an inappropriate posture while using their mobile devices [2]. The greater the amount of neck flexion that occurs during smartphone usage, the more stress is placed onto the spine, which causes neck pain [2]. Those with poor cervical spine stability may not ony suffer neck pain, but also whiplash-associated disorders and headaches [3-5].

Recent studies have shown that the automatic feedfor- ward mechanism of the deep flexor muscles in patients with cervical spine pain does not occur normally and that the deep cervical flexor muscle activation is delayed [6].

The deep neck flexor (DNF) muscles provide stability to the cervical spine during head and cervical spine movements [7]. Deep neck flexor endurance (DNFE) is an important component of cervical spine function [8].

To ensure that the cervical spine is functioning normally, an easy and precise method of testing the deep cervical flexor muscle endurance is needed. In previous studies, deep neck flexor endurance test (DNFET) was performed on healthy adults and showed that the electromyography (EMG) signals of the deep neck muscles were increased and

Received: 4 October, 2018 Revised: 21 November, 2018 Accepted: 23 November, 2018

Corresponding author: Dong-kwon Seo (ORCID https://orcid.org/0000-0002-3328-4922)

Department of Physical Therapy, College of Medical Science, Konyang University, 158 Gwanjeodong-ro, Seo-gu, Daejeon 35365, Republic of Korea Tel: 82-42-600-8457 Fax: 82-42-600-8408 E-mail: dkseo77@konyang.ac.kr

(c) This is an Open-Access article distributed under the terms of the Creative Commons Attribution Non-Commercial License (http://creativecommons.org/licenses/ by-nc/4.0) which permits unrestricted non-commercial use, distribution, and reproduction in any medium, provided the original work is properly cited.

Copyright $\odot 2018$ Korean Academy of Physical Therapy Rehabilitation Science 
that the sternocleidomastoid and anterior scalene muscles remained relatively inactive [9-11]. In the previous studies, the intra-rater reliability (intraclass correlation coefficient, $\operatorname{ICC}[3,1]=0.82-0.91)$ and inter-rater reliability (ICC $[2,1]=$ 0.67-0.78) for DNFET have already been established [12].

In previous studies, standard data had been obtained by conducting DNFET on American participants [13,14]. However, the generalized data from the United States cannot be applied to Korean citizens because there is not enough research to verify that the experimental data for the United States can be applied to other countries. Several previous studies also examined the relationship between DNECT time and sex, but the results were diverse.

The DNECT standard data study of Domenech et al. [14] showed a significant difference between gender and DNFET time. However, in a study by Jarman et al. [13], there was no significant difference between gender and DNFET time. Therefore, the purpose of this study was to be the first to collect DNECT standard data from Korean college students, and secondly, to provide objective indicators by comparing DNFET between men and women.

\section{Methods}

\section{Subjects}

The G-power program was used to calculate the number of subjects required. The independent t-test was used to asssess significant differences between groups using effect sizes $($ Cohen's $d)=0.65$, power $=0.8$, and significance level $(\alpha)=0.05$. Each group included thirty-nine subjects resulting in with a total number of seventy-eight subjects included in this study.

The selection criteria of subjects was as follows: (1) those with no pain in the neck at all times (2) college students ages 18 to 26 years old with an Korean nationality (3) those with no issues with lying on the bed for 30 minutes. The exclusion criteria was: (1) present neck pain or deformity, (2) those who have been diagnosed with concussion, (3) those who have had spinal surgery, (4) those who are currently restricted in their daily activities due to headaches (5) those with a history of cancer, (6) those who cannot lie flat on a bed due to excessive flexion of the spine. The subjects who were recruited were excluded from the experiment if any of the above exclusion criteria were applicable. A total of $78 \mathrm{sub}-$ jects (39 males and 39 females) were recruited.

The study was approved by the Institutional Review Board of the University of Kanyang (assignment No.
2017-062). All subjects received a full explanation of the deep neck endurance test and provided their informed consent.

\section{DNFET procedure}

The DNFET was performed in the same manner as in the previous studies $[13,14]$. The subject laid supine (hookedlying position) with both feet in contact with the table with the knees bent, both hands placed comfortably on the belly, and the head positioned in centerline of the body.

The subject maintained the chin tucked in an isometric position with maximum force and lifted the head and neck off the table by approximately $2.5 \mathrm{~cm}$. The evaluator overlapped the index finger and middle finger and while in contact with the back of the subjects head, the evalutor and drew a line approximately $1 \mathrm{~cm}$ long horizontal to the horizontal wrinkles on the anterior-posterior side of the neck with a marker (Figure 1).

Then the measurer instructed the subject to, 'Lift your head and pull your chin. At this time, you must maintaing your head in contact with my fingers'. The subjects were allowed to maintain contact with the evaluator's fingers but without placing the weight of their head by lifting the head and mainting the chin-tuck position.

At the end of the assessment, subjects were allowed to rest for 5 minutes, were instructed to avoid lifting the head from the bed during the rest period, and were allowed to lightly rotate the neck within the pain-free range.

During the DNFET operation, it was judged that out of the 3 , at least 1 error that was greater than 1 second could have occurred.

When the subject no longer was able to tuck the chin in

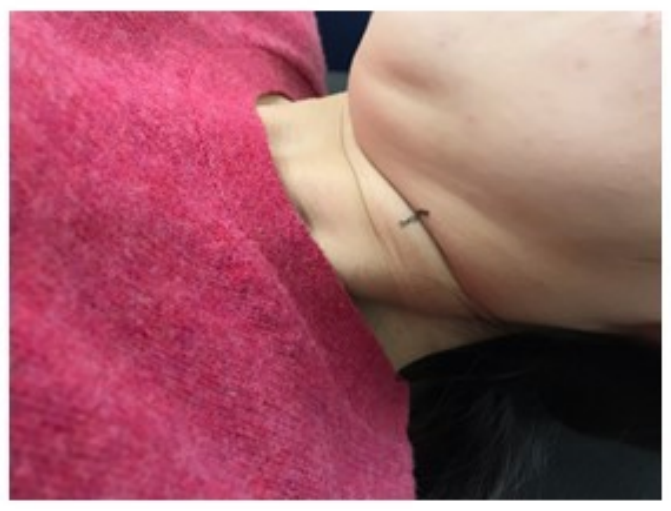

Figure 1. Deep neck flexor muscle endurance measurement (normal). 
and the perpendicular line no longer touched the neck line (Figure 2) [2]. When the head weight of the subject is felt on the overlapping finger of the subject [3], when the subject was no longer in contact with the hand When lifting your head without keeping. At the time of error, the evaluator instructed the subject to correct the error through verbal instructions. If an error occurred twice, the measurer records the time and ends the measurement.

However, if the subject wanted to end the assessment even if no error occurred, the evaluator recorded the time and finished the measurement.

The DNFET was performed a total of two times after two exercises of 5 seconds each before the measurement. A 5 -rest period was provided between the practice and assessment periods. If an error occurred during the training period, the subject's posture was corrected by verbal instructions. After the second training session and 5 minutes of rest, the timer on the stopwatch began the moment the subjects lifted their heads (Figure 3).

The measurement was performed only twice in order to take into account the learning curve [4,14]. Similarly, at the time of evaluatoin, the posture was corrected through one verbal instruction when an error occurred and when a second error occurred or the subject wanted to stop the experiment, the evaluation was terminated and the time was recorded.

After the first measurement, a 5-minute rest interval was provided, and the second measurement was performed. The mean values of the two measurements were obtained.

In order to ensure the inter-rater reliability before the experiment, each of the three evaluators asessed the 10 subjects. The subjects were instructed to be evaluated from one evaluator and then by a different evaluator.

Each participant was assessed during two training ses-

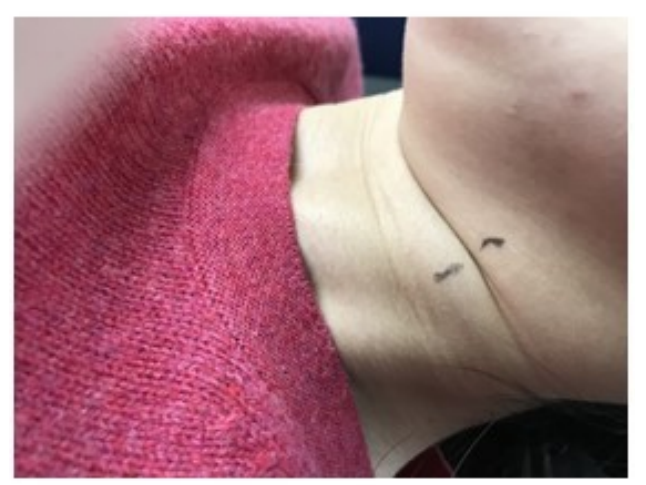

Figure 2. Deep neck flexor muscle endurance measurement (abnormal). sions and two evaluating sessions as well as given a five-minute resting period between training sessions.

\section{Statistical analysis}

Measurement results were analyzed using PASW Statistics ver. 18.0 software (IBM Co., Armonk, NY, USA). Descriptive statistics were used to identify the demographic characteristics of college students. The ICC was used to confirm the inter-rater reliability of the three evaluators. The independent t-test was used to identify significant differences between male and female subjects. The significance level $\alpha$ for confirming all statistical significance was less than 0.05 .

\section{Results}

A total of seventy-eight college students $(20.46 \pm 2.16$ years) participated in the study (Table 1). The inter-rater reliability was high with $\operatorname{ICC}(2,3)=0.785$ (95\% confidence interval $[\mathrm{CI}], 0.370-0.942)$. The mean \pm standard deviation of the DNFET time scores for men and women were $25.14 \pm 9.96$ seconds and $15.23 \pm 6.10$ seconds (Table 2). There was a significant difference in average DNFET time between men and women $(p<0.001)$.

\section{Discussion}

To test the activity of DNF, an ultrasound or EMG should be performed [9-11]. This cannot be implemented without equipment, and the equipment is expensive. In addition, the evaluator has to learn how to operate the equipment and analyze the data for a certain period of time. Although the reli-

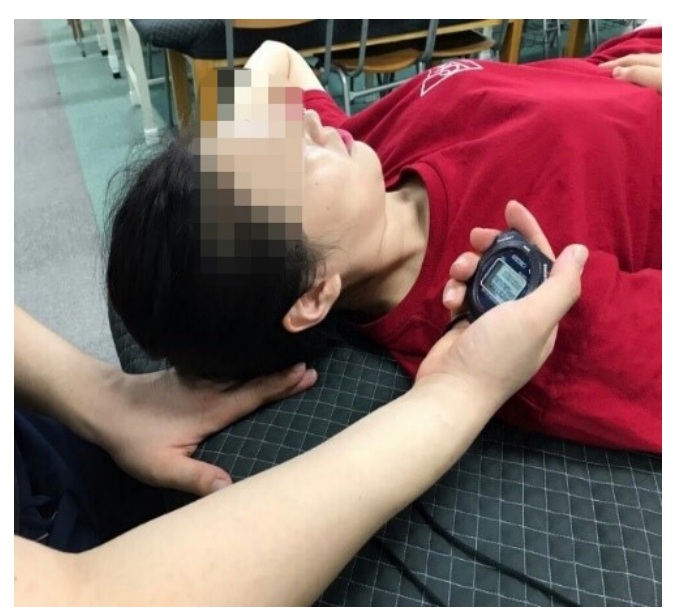

Figure 3. Deep neck flexor muscle endurance hold time measurement. 
Table 1. Demographic characteristics of the subjects $(\mathrm{N}=78)$

\begin{tabular}{lccc}
\hline \multicolumn{1}{c}{ Group } & Age $(\mathrm{y})$ & Height $(\mathrm{cm})$ & Weight $(\mathrm{kg})$ \\
\hline Male $(\mathrm{n}=39)$ & $20.46(2.16)$ & $174.97(6.30)$ & $71.05(8.98)$ \\
Female $(\mathrm{n}=39)$ & $19.46(1.08)$ & $161.51(5.12)$ & $54.28(7.86)$ \\
Entire sample $(\mathrm{n}=78)$ & $19.96(1.78)$ & $168.24(8.85)$ & $62.67(11.9)$ \\
\hline
\end{tabular}

Values are presented as mean (SD).

ability of DNFET has been established in previous studies $[13,14]$, it is difficult to evaluate the patient by comparing the DNFET results with the results of the study until the standard data of the subjects without neck pain are established $[4,12]$. This is the first study to apply DNFET to Korean people and present a baseline for applying DNFET measurement results directly to Koreans.

In this study, the reliability between the three instruments was highly reliable. In addition, the inter-rater reliability of this study was $9 \%$ and $16 \%$ higher than the inter-rater reliability of Jarman et al. [13] and Domenech et al. [14], respectively.

In the studies of Domenech et al. [14] and Jarman et al. [13], the clinicians had an average of 23 years and 13.5 years of experience, respectively. In this study, however, three third-year junior students assessed the inter-rater reliability. Therefore, the DNFET is a highly reliable tool that can be used to assess patients by evaluators with minimal clinical expereince.

The average DNFET results of Korean college students without neck pain were measured to be approximately $52 \%$ lower than the DNFET results of American subjects. In a study conducted by Domenech et al. [14], mean DNECT values for men and women without neck pain between 20 and 40 years were 38.4 and 23.1 seconds, respectively.

There are two possible explanations for this result. The first is that Koreans are less physical active than Westerners. More than half of Korean adults say that they meet the recommended amount of physical activity (at least 3 days a week, at least 30 minutes a day, at least moderate physical activity) [15].

Korean students spend prolonged periods of time sitting at their desk while studying independently to night starting from adolescence. In addition, physical education classes are recognized as insignificant and are often replaced by in-class or other important lessons [16].

In addition, less than $5 \%$ of Korean youths participate in Moderate to Vigorous Intensity Physical Activity, which is recommended by the World Health Organization for more
Table 2. Deep neck flexor endurance test $(\mathrm{N}=78)$

\begin{tabular}{lccc}
\hline \multicolumn{1}{c}{ Group } & DNFET (s) & DNFET min (s) & DNFET max (s) \\
\hline Male $(\mathrm{n}=39)$ & $25.14(9.96)$ & 9.02 & 54.94 \\
Female $(\mathrm{n}=39)$ & $15.23(6.10)$ & 6.76 & 32.58 \\
$\mathrm{t}$ & $5.233^{*}$ & & \\
\hline
\end{tabular}

Values are presented as mean (SD) or number only.

DNFET: deep neck flexor muscle endurance, min: minimum, max: maximum.

${ }^{*} p<0.001$.

than 60 minutes every day, and their numbers were lower than students from other Asian countries [17,18]. Second, Koreans are accustomed to sitting on the floor sitting with their legs crossed.

A human epidemiologic study has also been reported in which sitting the crossed legs on the floor reduces lumbar lordosis and posterior rotation of the pelvis compared to standing or sitting [19,20]. Forward Head Posture (FHP) may appear in the cervical spine as a result of decreased lumbar lordosis and increased kyphosis.

In women with FHP, the isometric force of the head neck flexion and extension muscle ratio was smaller than that of the women with normal neck flexion [21]. Patients with FHP may have less muscle activation of Longus Colli compared to healthy adults, and FHP may have a a negative effect on neck endurance [22].

In an American study, studies conducted by Domenech et al. [14] reported a significant difference in DNFET outcome according to gender but not in Jarman et al. [13] studies. In Korean college students, gender affected DNFET results as well as the results of Domenech et al. [14].

Differences in physical activity between men and women can also contribute to the DNFET results. In a study investigating physical activity for Korean college students, the average sitting time per day for male college students and female college students was approximately 784 minutes and 937 minutes, respectively. In addition, $42.5 \%$ of male college students and $66.5 \%$ of female college students responded that they lacked physical activities [18,23].

The limitation of this study is that it is difficult to generalize the results of the study because only college students from one university were selected. In future studies, we hope to expand DNFET research to university students and Koreans of all ages from various regions without neck pain, and to recruit a larger number of subjects.

Domenech et al. [14] showed no significant difference between physical activity and DNFET. However, consider- 
ing that the amount of physical activity of Koreans is different from the amount of physical activity of Westerners, the result of previous research that there is no difference between the two may be difficult to apply to Korean citizens $[15,18]$. Therefore, in future research, we hope to investigate the relationship between DNFET and physical activity.

In this study, the mean value of DNFET was lower in Koreans than in westerners and was lower in women than men. This results of this study suggests that the DNFET should be used to obtain objective data from patients with neck soreness and pain and it is hoped that it can be used as evidence to promote increased physical activity in Korean women.

\section{Conflict of Interest}

The authors declared no potential conflicts of interest with respect to the authorship and/or publication of this article.

\section{References}

1. Côté P, Cassidy JD, Carroll L. The Saskatchewan Health and Back Pain Survey. The prevalence of neck pain and related disability in Saskatchewan adults. Spine (Phila Pa 1976) 1998;23: 1689-98.

2. Cuéllar JM, Lanman TH. “Text neck": an epidemic of the modern era of cell phones? Spine J 2017;17:901-2.

3. Janda V. Muscles and cervicogenic pain syndromes. In: Grant R, editor. Physical therapy of the cervical and thoracic spine. New York: Churchill Livingstone; 1988.

4. Olson LE, Millar AL, Dunker J, Hicks J, Glanz D. Reliability of a clinical test for deep cervical flexor endurance. J Manipulative Physiol Ther 2006;29:134-8.

5. Falla D, Jull G, Hodges PW. Feedforward activity of the cervical flexor muscles during voluntary arm movements is delayed in chronic neck pain. Exp Brain Res 2004;157:43-8.

6. Jull G, Barrett C, Magee R, Ho P. Further clinical clarification of the muscle dysfunction in cervical headache. Cephalalgia 1999; 19:179-85.

7. Mayoux-Benhamou MA, Revel M, Vallée C, Roudier R, Barbet JP, Bargy F. Longus colli has a postural function on cervical curvature. Surg Radiol Anat 1994;16:367-71.

8. Stemper BD, Yoganandan N, Pintar FA. Influence of muscle contraction on whiplash kinematics. Biomed Sci Instrum 2004;40: 24-9.

9. Amiri M, Jull G, Bullock-Saxton J, Darnell R, Lander C. Cervical musculoskeletal impairment in frequent intermittent headache. Part 2: subjects with concurrent headache types. Cephalalgia 2007;27:891-8.

10. Jull G, Amiri M, Bullock-Saxton J, Darnell R, Lander C. Cervical musculoskeletal impairment in frequent intermittent headache. Part 1: subjects with single headaches. Cephalalgia 2007;27:793-802.

11. O'Leary S, Cagnie B, Reeve A, Jull G, Elliott JM. Is there altered activity of the extensor muscles in chronic mechanical neck pain? A functional magnetic resonance imaging study. Arch Phys Med Rehabil 2011;92:929-34.

12. Harris KD, Heer DM, Roy TC, Santos DM, Whitman JM, Wainner RS. Reliability of a measurement of neck flexor muscle endurance. Phys Ther 2005;85:1349-55.

13. Jarman NF, Brooks T, James CR, Hooper T, Wilhelm M, Brismée JM, et al. Deep neck flexor endurance in the adolescent and young adult: normative data and associated attributes. PM R 2017;9:969-75.

14. Domenech MA, Sizer PS, Dedrick GS, McGalliard MK, Brismee JM. The deep neck flexor endurance test: normative data scores in healthy adults. PM R 2011;3:105-10.

15. Cho MH. Are Korean adults meeting the recommendation for physical activity during leisure time? J Phys Ther Sci 2014;26: 841-4.

16. Lee KC, Cho SM, Pedagogy S. The Korean national curriculum for physical education: a shift from edge to central subject. Phys Educ Sport Pedag 2014;19:522-32.

17. WHO. Global recommendations on physical activity for health. Geneva, Switzerland: World Health Organization; 2010.

18. Choi JY, Chang AK, Choi EJ. Sex differences in social cognitive factors and physical activity in Korean college students. J Phys Ther Sci 2015;27:1659-64.

19. Bae JS, Jang JS, Lee SH, Kim JU. A comparison study on the change in lumbar lordosis when standing, sitting on a chair, and sitting on the floor in normal individuals. J Korean Neurosurg Soc 2012;51:20-3.

20. Lord MJ, Small JM, Dinsay JM, Watkins RG. Lumbar lordosis. Effects of sitting and standing. Spine (Phila Pa 1976) 1997;22: 2571-4.

21. Bokaee F, Rezasoltani A, Manshadi FD, Naimi SS, Baghban AA, Azimi H. Comparison of isometric force of the craniocervical flexor and extensor muscles between women with and without forward head posture. Cranio 2016;34:286-90.

22. Childs JD, Cleland JA, Elliott JM, Teyhen DS, Wainner RS, Whitman JM, et al. Neck pain: clinical practice guidelines linked to the International Classification of Functioning, Disability, and Health from the orthopaedic section of the American Physical Therapy Association. J Orthop Sports Phys Ther 2008;38:A1-34.

23. Chung N, Park HY, Park MY, Hwang YY, Lee CH, Han JS, et al. Association of daily physical activity level with health-related factors by gender and age-specific differences among Korean adults based on the sixth (2014-2015) Korea National Health and Nutrition Examination Survey. J Exerc Nutrition Biochem 2017; 21:30-8. 